\title{
PROPUESTAS PARA UN REPLANTEAMIENTO METODOLÓGICO EN EL ESTUDIO DE LAS RELACIONES DE LITERATURA Y CINE. EL MÉTODO COMPARATIVO SEMIÓTICO-TEXTUAL
}

\author{
José María PAZ GAGO \\ Universidade da Coruña
}

En un ensayo sobre metodología crítica, redactado por Umberto Eco en 1963 a petición del Time Literary Supplement para la serie The Critical Moment, el semiólogo italiano justificaba su interés central por la Historia de las Poéticas postulando que, en la investigación estética, debería partirse de una fenomenología de las distintas concepciones del arte presentes en los artistas y en las corrientes de los diversos países y las distintas épocas. Esta metodología fenomenológica y textual, en la que se determina la poética implícita en cada obra y en cada artista como postulaba Eco (1970: 278), debe constituir el núcleo del proceder investigador en el estudio de las relaciones de la literatura y el cine, en el marco general de la Teoría de la Literatura y de la Literatura Comparada.

En esta línea, hace una década que vengo propugnando un replanteamiento metodológico global para fundamentar un estudio riguroso y 
coherente de las complejas relaciones entre novela o teatro y cine, cuya manifestación más frecuente es la práctica de las transposiciones. Este tipo de relaciones interartísticas entran de lleno en los intereses científicos de la nueva literatura comparada y, por esta razón, he tratado de desarrollar el llamado método comparativo semiótico-textual, como un método expositivo y analítico especialmente adecuado para abordar los procesos transpositivos.

En una primera fase, se trata de analizar el texto fílmico y el texto novelístico independientemente, de acuerdo con sus respectivos sistemas semióticos de expresión, como obras de arte autónomas entre las que no existe relación ni de jerarquía ni de dependencia, como parece implicar el término usual de adaptación que, en mi opinión, debe ser reemplazado.

Sólo posteriormente tiene sentido el estudio comparativo en el que deberán analizarse tanto los rasgos cinematográficos presentes en el relato verbal, que recurre a técnicas narrativas y descriptivas comunes para inscribir la visualidad en el texto o para configurar la estructuración de la intriga, como las huellas de la narración verbal en el texto fílmico a través de narradores extradiegéticos mediante voz en off o de narradores intradiegéticos cuya función es asumida por una voz over o por algún personaje. Desde una perspectiva comparatista, deben tenerse en cuenta, pues, tanto las convergencias y divergencias de texto narrativo verbal y texto narrativo fúlmico como sus mutuas interferencias.

\section{LA LITERATURA COMPARADA COMO MARCO METODOLÓGICO}

Como es de sobra sabido, la literatura comparada clásica se resistió a considerar como objeto de sus investigaciones las relaciones entre literatura y cine. El cine sería un arte nuevo, popular y masivo, tecnificado e industrializado, y por tanto poco prestigioso al lado de sistemas de expresión artística de tanta raigambre y nobleza como la literatura, de la que además intentaría aprovecharse este arte inmaduro y artificial para obtener lustre e historias que contar. Ni la historia literaria, ni la crítica ni la misma literatura comparada dieron la relevancia necesaria a las relaciones del cine con la literatura ( $c f$. Clerc, 1989, 1994: 237 y Peña-Ardid 1992: 44 y ss.). 
Un tanto tautológicamente, define Remak (1961: 1) la literatura comparada como «la comparación de una literatura con otra u otras, y la comparación de la literatura con otras esferas de la expresión humana», definición reivindicada por Mortier (1981: 12) dos décadas más tarde como la mejor de la disciplina, en el ámbito de un Congreso de la Asociación Internacional de Literatura Comparada (Villanueva, 1994: 106). Previamente, se ofrece una larga enumeración de esas esferas de la expresión, para precisar los ámbitos del «estudio de las relaciones entre la literatura y otras áreas de conocimiento y creencias, como las artes (por ejemplo, pintura, escultura, arquitectura, música), la filosofía, la historia, las ciencias sociales (verbigracia, ciencia política, economía, sociología), las ciencias experimentales, la religión, etc.». Aunque citan áreas tan alejadas del fenómeno literario como la economía o las ciencias experimentales, Remak y Mortier olvidan el cine. Pichois y Rousseau, por su parte, conciben la literatura comparada como «el arte metódico, a través de la investigación de los lazos de analogía, de parentesco y de influencia, de aproximar la literatura a otros dominios de expresión o de conocimiento...» (1967: 174), pero tampoco aluden el arte cinematográfico.

Estas propuestas definicionales no dejan de abrir las puertas, tardíamente, a la consideración comparatista de la literatura y el cine, como señala Urrutia (1984: 7), pero sólo lo hacen de forma implícita, al referirse a las relaciones de la literatura con otros tipos de expresión artística, sin citar el cine como campo privilegiado. La cosa es más curiosa si tenemos en cuenta que la reflexión estética había aportado una temprana valoración artística del cine, considerado desde principios de siglo como el Séptimo Arte, fusión y conciliación de todas las demás, según el Manifiesto de las Siete Artes, redactado por Ricciotto Canudo en 1911 (Romaguera y Alsina, 1993: 18). A finales de los sesenta, persiste la obcecación de los comparatistas en volver sus espaldas al cine, e incluso renovadores de la disciplina como Rene Wellek (1964) preferirán recurrir a una Historia Comparada de las Artes para abordar las relaciones de éstas con la literatura, opinión que comparte Ulrich Weisstein (1968 en 1975: 52) al proponer la consideración de formas mixtas como la ópera, la cantata, el cómic o el cine en una posición muy excéntrica con respecto al comparatismo literario.

Las relaciones de la literatura y el cine sólo entrarán por derecho propio en el ámbito de la nueva literatura comparada, la del nuevo paradigma (Fokkema, 1982), que protagoniza un giro desde las posiciones historicis- 
tas y genetistas hacia las tendencias teórico-críticas dominantes en los estudios literarios a partir de la segunda mitad del siglo XX, especialmente en el área académica americana que se distancia de la más inmovilista área de influencia francesa. En el dominio académico francés, en efecto, Jean Marie Clerc rebatía «el repliegue del investigador al terreno único y restringido de las bellas letras» «y la exclusión de los restantes aspectos culturales y artísticos de una época, deplorando» la estrechez del campo estrictamente lingüístico en el que se acantonan muchos estudios comparatistas, dejando escapar un medio (las imágenes modernas) de acercamiento esencial para comprender la modernidad» (1989, en 1994: 236).

Clerc se pregunta, tras invocar la definición de Pichois y Rousseau (1967), si no compete a la literatura comparada, desde la amplitud de los campos de estudio a los que conducen los sistemas de interacciones que analiza, también lo que él llama las imágenes modernas procedentes de los medios de reproducción mecánica. El comparatista galo propone volver a situar en este horizonte prioritariamente icónico las manifestaciones de la literatura actual, precisando los intercambios y transferencias producidas. Sólo de este modo podría abordarse un estudio coherente y riguroso de las relaciones entre imagen y palabra, desde una renovada literatura comparada, pues sólo ella dispone de las herramientas de investigación necesarias para llevar a cabo investigaciones simultáneas en los dos frentes (Clerc, 1994: 237).

En este contexto comparatista riguroso, que incorpora un componente teórico-literario fundamental, se sitúan las principales líneas de investigación sobre la relación entre texto literario y texto fílmico. Se trata ante todo de una renovación epistemológica y, en consecuencia, también de una renovación metodológica urgente, no sólo en el terreno general del comparatismo, sino especialmente en el terreno de la convergencia discursiva literaria y cinematográfica, cuyo estudio se ha limitado tantas veces a los enfoques temáticos y argumentales, ideológicos y espirituales, cuando no a las clasificaciones, enumeraciones y taxonomías varias o a los juicios de valor sobre la aconsejable fidelidad y la execrable infidelidad de la adaptación al modelo literario o a su tantas veces mentado espíritu, como si de un matrimonio o un voto religioso se tratase. 


\section{INTERDISCIPLINARIEDAD}

Una aproximación de este tipo debe tener muy en cuenta su carácter interdisciplinar y transdisciplinar, recurriendo en estas descripciones empíricas a disciplinas y métodos diversos: la semiótica, la narratología y el análisis textual tanto literario como fílmico; la historia literaria y del cine, la sociología cinematográfica o la psicología cognitiva, en el marco unitario y global de la Teoría de la Literatura y la Literatura Comparada .Al enunciar los principios básicos de la nueva literatura comparada, en efecto, Tötösy de Zepetnek cita el principio comparatista de la interdisciplinariedad, vinculándolo directamente al método. Si el principio del método se refiere a la aplicación de marcos teóricos y metodológicos, tanto propios como de otras disciplinas, para la adquisición de conocimientos en el análisis de la literatura y del texto literario, el comparative principle of interdisciplinarity in literary studi hace alusión a los marcos conceptuales aportados por la historia, la psicología y otras áreas de la expresión artística como el cine, la música, las artes visuales, etc. (1998: 79). La apertura a nuevos campos y soportes como las viejas y las nuevas tecnologías de la comunicación, desde el cine o la televisión a las redes informáticas, viene exigida por la integración de los estudios comparatistas en el paradigma contemporáneo de la Ciencia literaria, participando de las corrientes y tendencias más recientes, con la consecuente revisión y actualización de sus métodos, siempre diversos y plurales, y de su terminología, que debe ganar en precisión y en matización.

Corrientes teóricas tan trascendentales en el siglo XX como la Semiótica literaria y fílmica, la Hermenéutica fenomenológica, la Pragmática de la literatura y las Teorías de la recepción, la Teoría de los polisistemas o la Ciencia empírica de la literatura inspiran y dirigen esta necesaria renovación de un ámbito de la disciplina hoy tan pujante, tal como la propugnan las últimas generaciones de comparatistas, de Jorge Urrutia (1984) y JeanMarie Clerc $(1985,1989)$ a Darío Villanueva (1994 y 1999a, 1999b) ${ }^{1}$ o Steven Tötösy de Zepetnek (1998 y 1999), por citar unos pocos nombres señeros de los ámbitos francés, norteamericano e hispánico.

\footnotetext{
${ }^{1}$ Villanueva es contundente cuando afirma sin ambages que la relación con el cine es uno de los campos más interesantes que la literatura comparada admite y justifica (1994: 107).
} 
Puesto que convenimos con Tötosy de Zepetnek (1998: 80) en que el estudio comparatista debe ser necesariamente interdisciplinar, en las tres acepciones que incluye en su opinión el término (intradisciplinar, multidisciplinar y pluridisciplinar), esas y otras escuelas aportarán los métodos y perspectivas más útiles a la investigación de las relaciones entre literatura y cine. La Semiótica, y muy particularmente la Semiótica narrativa o Narratología, contribuyeron decisivamente a describir el funcionamiento comunicativo y narrativo del cine. El punto de partida esencial estriba en la narratividad que comparten dos sistemas semióticos distintos, el verbal literario y el visual cinematográfico, razón por la cual la Narratología Comparada se ha revelado como un instrumento eficaz para abordar el estudio de ambos sistemas de narración ficcional. De hecho, la mayor parte de los manuales sobre análisis textual fílmico aparecidos en la pasada década (Aumont y Marie, 1988; Casetti y de Chio, 1990; Carmona, 1991; González Requena, 1995) coinciden todos ellos en tomar como fundamento teórico la semiótica textual, remontándose al postulado de Metz, según el cual el verdadero estudio del sentido del film debe necesariamente suponer el estudio de la forma de su contenido. Tal perspectiva semiótica aborda el análisis de los significantes fílmicos y de los códigos que los organizan en el discurso cinematográfico, aportando las necesarias condiciones de rigor, objetividad y cientificidad al método.

Una vez superada la etapa más formalista de la primera Narratología, esta subdisciplina semiótica ha sabido mantener su validez y eficacia, incorporando e incorporándose al mismo tiempo a las perspectivas más recientes de la Semiótica del Cine para continuar ejerciendo, cada vez en mayor medida, su función analítica y despriptiva, como reconocía Chateau (1990: b7): «la narratologie, elle est sans doute la branche actuellement la plus florisante de la sémiologia du cinéma». Particularmente, la evolución de la Narratología fílmica postestructuralista en confluencia con la orientación pragmática que tomaron los estudios semióticos a la luz de la redescubierta obra de Peirce, han convertido las teorías de la enunciación y la recepción del texto fílmico en núcleo central de las investigaciones y discusiones que animan actualmente los debates teóricos.en el contexto de la Semiótica Fílmica que he llamado de segunda generación (Paz Gago, 2002).

Además de las estrategias metodológicas del análisis de los textos novelístico y fílmico, el posterior proceso comparativo a partir de la consideración del guión literario, es muy interesante e iluminador tener en 
cuenta las reflexiones y opiniones, las teorizaciones cuando existan, de escritores y cineastas, especialmente ante experiencias fenomenológicas como la escritura de guiones adaptados o las transposiciones de sus propios relatos, con su posible colaboración en la redacción del guión o la realización y dirección de una película.

Quizás uno de los mejores guionistas de la historia del cine, colaborador estrecho de cineastas como Buñuel o Godard, Jean Claude Carrière señalaba también la relevancia de esta aproximación pluridisciplinar y diversa, que acopia ingredientes múltiples de un objeto de investigación tan complejo como poliédrico: «La historia del cine, el análisis riguroso de las películas, el encuentro con cineastas vivientes, el estudio minucioso de los guiones y la comparación punto por punto con los filmes nacidos de ellos, todas esas tareas tienen una importancia evidente» (Carrière, 1998: 10). Tanto Cattrysse (1992) como, más recientemente, Pérez Bowie (2003: 11) recordaban la amplitud y heterogeneidad de los contenidos que abarcan estos estudios, desde la adaptación fílmica o las relaciones de los escritores con el cine, a los estudios de carácter general, histórico, didáctico o metateórico.

En un auténtico manifiesto del nuevo Comparatismo literario, Tôtôsy de Zepetnek fundamenta la aproximación a la literatura en su relación con el cine desde las perspectivas especialmente fecundas en el terreno comparatista de la Teoría de polisistemas y la Ciencia Empírica, ya experimentada con muy buenos resultados por Cattrysse (1992a, 1992b, 1994a, 1994b), que ha tenido continuidad, entre nosotros, en la obra Luis Miguel Fernández (2000) sobre las adaptaciones del Don Juan.

Son éstos algunos de los elementos teóricos y analíticos que intervendrán en mi propuesta metodológica interdisciplinar para estudiar científicamente las complejas relaciones que desde hace un siglo han entablado sistema narrativo literario y sistema narrativo fílmico. El contraste continuo de los modelos teóricos y los análisis textuales es la estrategia más útil y adecuada para calibrar la validez de los planteamientos hasta ahora esbozados, en ese incesante intercambio de datos e hipótesis, análisis y deducciones en que, en mi opinión, debe consistir todo trabajo científico riguroso. 


\section{EL MÉTODO COMPARATIVO SEMIÓTICO-TEXTUAL}

Un estudio comparatista riguroso de la literatura y el cine debe contar con un método adecuado. A menudo, este tipo de trabajos se han limitado a comentarios temáticos y argumentales, cuando no valorativos y casi judiciales o morales, juzgando el valor de la novela por encima de su versión fílmica, o ésta en función exclusiva de su fidelidad a aquélla, convirtiendo en un dato incontrovertible lo que no son más que cuestiones de gusto, de parecer subjetivo o del prejuicio que supone considerar la literatura como un arte superior a las más recientes artes visuales.

El nuevo enfoque comparatista que aquí se propugna debe tener en cuenta lo que de común hay en la literatura y el cine para, a partir de esa comunidad de rasgos compartidos, analizar sus diferencias y valorarlas objetivamente, sin entrar en bondades o maldades, peores o mejores, juicios casi siempre intuitivos e impresionistas, ajenos en todo caso a lo que debe ser una tarea analítica y hermenéutica fundamentada en datos textuales y en descripciones someras de índole tanto formal y estructural como pragmática o funcional. El punto de partida, pues, será poner de relieve las convergencias entre ambos sistemas de expresión artística y también exponer sus divergencias. En caso contrario, se considerarán niveles, modalidades o sistemas de signos heterogéneos, lo cual no garantiza una comparación adecuada.

\subsection{Convergencia: el sistema narrativo ficcional}

La novela y el filme tienen en común dos rasgos definitorios esenciales: la narratividad y la ficcionalidad. Estas dos propiedades, pues, constituyen la base del estudio comparativo de ambas modalidades expresivas, literaria y cinematográfica, el fundamento que las aproxima y permite su comparación.

En Die Logik der Dichtung, Käte Hamburger hace una distinción radical entre el género mimético o ficcional y el género lírico o existencial. Junto a la ficción épica, la dramática y la narrativa o narración ficcional propiamente dicha, incluye Hamburger la ficción cinematográfica dentro de ese gran continente literario que es la ficción. Quizás para contradecir una vez más a su condiscípulo Roman Ingarden, que en La obra de arte literaria situaba el cine fuera de las fronteras de la literatura, justifica la fenómenologa alemana su audaz posición recurriendo al espectáculo tea- 
tral. Si parece fuera de lugar la consideración del cine en el marco de una lógica de la literatura ${ }^{2}$, también el teatro exige lo que Hamburger llama la fenomenología de la escena de modo que el factor técnico y fotográfico no sólo no impide, sino que refuerza la existencia del cine como forma de ficción y por tanto como forma literaria (1957, 1995: 148). Casi medio siglo más tarde, en este apasionante umbral entre los siglos y las artes, los signos y los géneros, un reciente estudio introductorio a los estudios literarios publicado en el Reino Unido por Mario Klarer, An Introduction of Literary Studies (1999), considera con toda naturalidad y sin dar ningún tipo de explicaciones por innecesarias, cuatro clases genéricas: fiction, drama, poetry y film.

Los interminables debates sobre las técnicas narrativas que la novela ha prestado al cine o que, por el contrario, éste ha descubierto al relato; sobre si tal estrategia aparentemente cinematográfica ya había sido explotada por la narrativa verbal anterior a la aparición del cinematógrafo o si tal otra la utiliza el cine sin haberla tomado de ninguna tradición de ficción escrita; la eterna cuestión de las influencias de la novela sobre el cine primero y del cine sobre la novela después, nos conducen a una hipótesis central: la narratividad es una propiedad abstracta, única y general, que poseen los diferentes lenguajes, cuyas posibilidades adoptan y adaptan los diversos sistemas expresivos para narrar historias. Existen una serie de técnicas estructurales, procedimientos y recursos narrativos para contar una historia, y esas estrategias narrativas son utilizadas por los diferentes sistemas de expresión, tanto verbal-oral (narrativa oral) como verbalescrito (novela o cuento) o visual-verbal (película de cine) y por sus respectivos sistemas semióticos, simbólicos y simbólico-indiciales.

Las técnicas narrativas son las mismas, las explote la novela o el cine, sistemas ambos de gran eficacia narrativa. De ahí que, según la muy autorizada opinión de Eco (1962, en 1970: 196-197), entre la narración verbal y la narración cinematográfica existe no una simple analogía, como se sostiene habitualmente, sino una auténtica homología estructural, pues ambas desarrollan de forma idéntica la estructura de la acción en intriga. En ambos casos existe una acción que es estructurada narrativamente,

2 Dichtung, designa en alemán tanto poesía como ficción (Erdichtung) aunque, como señala Gadamer, es la palabra alemana para toda forma de arte literario. 
independientemente de que en un caso la acción sea narrada verbalmente y en el otro sea, además, representada visualmente. Urrutia (1984: 72), por su parte, habla de estructuras narrativas abstractas que serían comunes y no específicas del cine o de la novela, sufriendo determinadas modificaciones según el soporte y el sistema semiótico de que se trate.

Esto explica que encontremos en la narrativa de la Antigüedad tardía, en los libros de caballerías, en las leyendas románticas o en la novela realista recursos narrativos y descriptivos que pueden parecer cinematográficos, pero que, evidentemente, no han sido tomados del cine, sino que se trata de los mismos procedimientos narrativos, de una forma común de estructurar las acciones de la historia manipulando su orden lógico, jugando con su duración, ampliándola o reduciéndola, etc. para lograr una intriga más original y atractiva a la razón de ser de todo discurso narrativo, el receptor. De ahí, que la escuela comparatista francesa del Pré-cinéma estudie con precisión inaudita los rasgos cinematográficos de obras literarias de todos los tiempos, desde la Eneida (Leglise, 1958) hasta Madame Bovary. En efecto, El Quijote o La Regenta, La Divina Comedia o Los novios, son obras que incluyen rasgos narrativos y descriptivos explotados habitualmente por el cine clásico y a nadie se le ocurriría pensar que el Dante, Cervantes o Clarín conocieron el Séptimo Arte; lo que ocurre es que, como afirma Fell en una obra clásica sobre «el filme y la tradición narrativa en la que éste se inserta conscientemente, las técnicas empleadas por el cine no le son propias sino que han sido tomadas de medios» como la novela del siglo XIX o como el teatro, especialmente del melodrama decimonónico (1977: 16).

Para contar una historia hay que presentarla discursivamente de una determinada forma, disponiendo las acciones de acuerdo con una determinada estructuración, la intriga. Existen diferentes procedimientos narrativos para disponer las acciones en intriga, de modo que la historia atraiga la atención del receptor, el cual trata de seguir su desarrollo: comienzos en media res, elipsis, tramas paralelas, alteraciones del orden temporal de la historia, flash back, aceleraciones del ritmo... Es cierto que determinados recursos narrativos pueden adaptarse mejor a un medio concreto, adecuarse a las posibilidades de un sistema semiótico dado y a sus códigos, pero lo que en realidad ocurre, tal como hace notar Villanueva, es que «algunos procedimientos narrativos que en la escritura novelística quedan un tanto «opacos» cobran en lo que podríamos llamar la «escritura fílmica» mucha mayor efectividad». Por razones históricas, 
efectivamente, el cine fue el primero en recurrir a la novela no sólo para encontrar historias ficcionales, sino también para aprender a contarlas, adaptando sus estrategias narrativas. A medida que el cine configura su propio lenguaje y se convierte en un fenómeno de comunicación artística de gran difusión, muestra a los novelistas sus nuevas posibilidades, más bien renovadas posibilidades, pues se trata de técnicas narrativas comunes que llegan «a través de su concretización fílmica, en palabras de Darío Villanueva (1999a: 189-190), por supuesto mucho más espectacular, es decir, comunicativamente marcada, que la novelesca, y desde esa nueva experiencia estético-receptiva escriben sus obra».

Organización de los planos concatenados en secuencias que configuran un filme en función del orden prefijado en el guión, el montaje constituye uno de los factores esenciales de la narratividad, pues, como señala Zunzunegui (1989: 161), se trata del principio organizativo que rige la estructuración interna de los elementos fílmicos visuales y/o sonoros. El montaje encuentra su modelo en una técnica narrativa básica que uno de los creadores del lenguaje cinematográfico, Griffith, tomó de la novela realista inglesa, en concreto de Dickens, tal como demostró Eisenstein en su célebre artículo sobre Griffith, Dickens y el cine de su tiempo (1944).

Todo sistema narrativo es temporal y lineal, de ahí que tenga que jugar continuamente con el tiempo y el espacio, manipulando la duración, el orden cronológico, el ritmo o la frecuencia. Así, el discurso narrativo debe constantemente eliminar tiempo de la historia que sería imposible reflejar en el marco necesariamente limitado de un relato o expresar acciones que suceden simultáneamente... problemas que debe resolver el texto narrativo sea novelístico o fílmico, recurriendo constantemente a las interrupciones en final de párrafo o de capítulo, los cortes típicos del montaje cinematográfico, con la funcionalidad o bien de suprimir parte del tiempo de la historia, la elipsis, o bien de introducir una acción que tiene lugar al mismo tiempo que la acción relatada y volver posteriormente a ella.

Es bien conocida la anécdota relatada por los biógrafos de Griffith y recogida por Eisenstein para demostrar la ascendencia novelística de lo que a primera vista parecen procedimientos ajenos a la narración verbal y exclusivos de la narrativa fílmica: cuando el cineasta presentó a los productores de la Biograph el guión de la película After many years, adaptación de poema narrativo de Tennyson Enoch Arden, éstos no salían de su asombro ante lo que juzgaban un disparate, pues a un plano de la protago- 
nista llorando la incierta suerte de su marido sucedía, tras un corte, otro plano de su consorte desterrado en una isla desierta; semejantes saltos en el espacio y en el tiempo resultarían del todo incomprensibles para el público. Para explicar lo que entonces parecía absurdo e ininteligible, Griffith recurrió a la gran tradición narrativa de la que había tomado el procedimiento, pues de esa forma exactamente escribían sus novelas Dickens o Flaubert y éstas funcionan exactamente igual que las películas, novelas en cuadros las llamará el cineasta, pues ambas son formas de contar historias, en un caso historias escritas y en otro historias fotografiadas, contadas con palabras las primeras, en imágenes las segundas (1986: 186) ${ }^{3}$.

La novela realista también recurre constantemente a la elipsis, mediante cortes más o menos bruscos, para eliminar tiempo de la historia, pues es prácticamente imposible la isocronía o correspondencia total entre duración temporal de la historia y del relato. Esa ruptura en la progresión de la acción es más brusca cuando se trata de provocar el efecto de simultaneidad temporal, alternando la narración de dos acciones que suceden en el mismo lapsus temporal de la historia, y de esa práctica dickensiana habría tomado Griffith, según Eisenstein, la técnica del llamado montaje alternado y su variedad, el montaje paralelo (cf. Mínguez, 1998: 29-30; Villanueva, 1999a: 190). En efecto, la técnica tan cinematográfica del crossing-upp o cross-cut, alternancia cruzada de planos que recogen situaciones simultáneas en espacios diferentes, encuentra sus antecedentes en la épica medieval y en la novela moderna, desde el Quijote hasta Madame Bovary.

Cuando don Quijote permanece en el palacio de los Duques y Sancho es enviado a la Ínsula Barataria, se plantea efectivamente en la novela de Cervantes el problema de relatar dos acciones simultáneas, problema que el narrador resuelve mediante la técnica del entrelazamiento, frecuente ya en el roman courtois francés. Esta estrategia consistente en intercalar sucesivamente fragmentos de la acción desarrollada en uno y otro ámbito espacial al mismo tiempo ha sido puesta de manifiesto por Darío Villanueva, quien explica cómo, al separarse los dos personajes, se alter-

3 Recogida de Linda A. Griffith, When the Movies Were Young, New York: Dutton \& Co., 1925: 66. Ramírez, G., El cine de Griffith, México: Era, 1972: 26. Las palabras del realizador transcritas por Eisenstein y su propia reflexión han sido comentadas por la mayor parte de los especialistas (Urrutia, 1984: 70; Company, 1987: 19; Mínguez Arranz, 1998: 29-30 y Villanueva, 1999a: 190). 
nan los relatos de lo que ocurre en los dos focos locales --el palacio y la ínsula-, con interrupciones sucesivas y frases de enlace entre ambas acciones, produciendo en el lector la sensación perfecta de que las dos son en realidad simultáneas (Villanueva, 1988: 32 y 1994: 52-53). Muy semejante a la técnica de cortes en que se basa el montaje, la articulación de fragmentos que relatan las dos intrigas simultáneas produce la impresión ficticia de que lo que leemos en progresión, como lo que vemos en la pantalla, corresponde a un mismo segmento temporal ( $c f$. Paz Gago, 1995).

Si la redacción de un guión cinematográfico significa un primer montaje o pre-montaje de la historia que se va a narrar, muchas obras literarias se asemejan a un auténtico guión de montaje: desde la Eneida, cuyo Primer Canto fue dispuesto en forma de guión técnico por Leglise (1958), a las novelas de Zola que, según Eisenstein (1933, 1972: 11), estaban escritas en forma cinematográfica, en planos y en forma de guión de montaje.

Aspecto central en la configuración del texto narrativo son las manipulaciones del orden temporal del relato con respecto a la historia, entre las cuales es la analepsis, introducción de acontecimientos anteriores al momento de la historia desde el que se cuenta, la modalidad más frecuente. La analepsis, que responde pues al mecanismo propio de la narración de hechos sucedidos con anterioridad al acto narrativo, encuentra su correspondencia en un procedimiento fílmico fundamental, el flash-back o retrospección temporal magistralmente inaugurada por Orson Welles en Ciudadano Cane. Estos flash-back analépticos constituyen una técnica estrictamente fílmica, mediante la cual un arte visual que en principio utiliza siempre el tiempo presente da continuos salto atrás en el tiempo, pero están presentes en la narrativa oral y verbal de todos los tiempos, desde la llamada novela bizantina o helenística (Villanueva, 1999a: 190) hasta la novela decimonónica, pasando por la épica medieval y la novela barroca. La anacronía contraria, en la que se anticipan acontecimientos posteriores, o prolepsis, encuentra también su correspondencia en la narración cinematográfica, el llamado flash-forward.

Cuando Mario Vargas Llosa afirma que todos los medios de la historia cinematográfica proceden de la novela, es porque ésta es muy anterior al cine y cinco siglos de existencia le han permitido experimentar todas las posibilidades narrativas y descriptivas posibles, las mismas que explotará el sistema narrativo cinematográfico. Tras la deuda contraída por el cine de los primeros tiempos, cuando éste se va desarrollando desde los años 
veinte, sus peculiares formas de narrar contagiarán a su vez a la novela, que habiendo usado los mismos procedimientos los recrea de nuevo a la luz proyectiva del nuevo arte narrativo. Es eso lo que ocurre con la novela de la Generación Perdida norteamericana, con el Nouveau roman francés o con el realismo. Lo que parecen hallazgos genuinamente cinematográficos no son más que los recursos habituales de la novela de todas las épocas, adaptados conscientemente por los primeros cineastas al sistema cinematográfico: el montaje se basa en la práctica necesaria de la elipsis como el flash-back es la versión audiovisual de las analepsis propias del tempo narrativo.

Hace cuarenta años, Eco exponía una conclusión que calificaba con toda cautela, valga la redundancia, de preliminar, cauta y, sobre todo, modesta. Hoy, después de cuatro décadas en las que cine y novela se han aproximado hasta fundirse y confundirse, esa conclusión puede exponerse con más contundencia y seguridad: «resulta posible establecer comparaciones entre la forma de un filme y la forma de una novela al menos en el plano de la estructuración de la acción» (1962, 1977: 199), no sólo resulta posible, sino que se viene haciendo con resultados muy halaguieños e interesantes y se trabaja cada vez con más esfuerzo en aquella posibilidad de investigación, que, como siempre, abría Eco con generosidad científica «para quien quiera profundizar más en el hecho de que en un determinado clima cultural distintas artes planteen problemas del mismo género con soluciones estructuralmente semejantes». Es ese camino de la homología narrativa inaugurado por el semiólogo italiano el que proponemos de nuevo para fundamentar los trabajos de investigación sobre narrativa literaria y narrativa audiovisual.

\subsection{Divergencia: el sistema semiótico}

Lo que diferencia al cine de la novela es el sistema semiótico que ambos utilizan para comunicarse con el receptor, espectador en el primer caso y lector en el segundo. Como señala Villanueva, la comparación entre literatura y otro tipo de expresión artística debe tener en cuenta que los signos empleados por una y otra son distintos, pero que pueden tender a la consecución de efectos significativos comunes. Consciente de que los estudios comparativos entre discurso fílmico y novelístico se limitan en ocasiones a cuestiones banales y superficiales, circunscribiéndose a planteamientos descriptivistas y enumerativos de intención didáctica, propone el teórico y comparatista com- 
postelano, el recurso a una metodología tan sólida y solvente como la semiología: no cabe duda también de que en la Semiótica, entendida como teoría general de los signos, puede buscar el comparatista los instrumentos metodológicos y la precisión conceptual que precisa (1994: 107).

De acuerdo con la naturaleza sígnica y textual de sus objetos, se distinguen dentro de la Semiótica General dos ámbitos epistemológicos complementarios aunque bien diferenciados: la Semiótica literaria, el campo más desarrollado desde la explosión de los estudios semiológicos en los años sesenta, y la Semiótica Visual, de aparición más reciente. Más que la teoría de la imagen y de los sistemas hipoicónicos e indiciales en general, sin duda son los estudios sobre el Cine los que constituyen el campo privilegiado de la investigación semiótica sobre un fenómeno muy particular de la semiosis visual.

El texto fílmico se basa en la imbricación de los sistemas de signos indiciales con los sistemas simbólicos, tanto verbales escritos u orales como visuales, desarrollando códigos específicos para dotar a las imágenes en movimiento de una alta capacidad narrativa y de una intensa potencialidad ficcional. Por esta similariddad de sus objetos, la Semiótica Fílmica se desarrolló paralelamente a la Semiótica del texto narrativo, lo que significó ventajas para la primera, pero produjo también interferencias metodológicas todavía no superadas. Además de esa vinculación a la Narratología, la Semiología del cine se apoyó en la Lingüística y posteriormente en la Semiología de la representación y del espectáculo. En efecto, constatadas las posibilidades representativas y narrativas del fílme, su doble condición de relato y de espectáculo, se aplican a su estudio las estrategias y los útiles metodológicos creados para la narración verbal y para el espectáculo teatral.

Desde que en 1933 Roman Jakobson dio a la expresión, hasta entonces de uso metafórico, lenguaje cinematográfico el significado literal de discurso cinematográfico como opuesto a discurso teatral, se inauguró la concepción semiótica del cine, que se ha convertido en el fundamento teórico más solvente en el ámbito de los estudios fílmicos. Para el padre de la Poética estructuralista, en efecto, «todo fenómeno del mundo externo se transforma en signo en la pantalla», de forma que en este texto tan temprano reivindica ya «la esencia sígnica de los elementos cinematográficos, organizados en un sistema de signos-objeto de naturaleza óptica y acústica» (Jakobson, 1933 en 1970: 154-155 y 157). 
Herederos de la amplia reflexión teórica que sobre el cine realizaron los formalistas eslavos, los semiólogos de la Europa occidental desarrollaron en los años sesenta la Semiótica fílmica que cumple ya su cuarenta aniversario, cuatro décadas en las que ha ido evolucionando al ritmo marcado por la evolución de las teorías semióticas lingüísticas y literarias fundamentalmente (Paz Gago, 2002). La primera Semiótica Fílmica se inspiró, en efecto, en una concepción de la Semiología como teoría lingüística, dos décadas, las de los sesenta y los setenta, en las que Saussure, Hjelmslev o Greimas proporcionaron el modelo teórico a seguir, a rechazar o a revisar para dar cuenta del lenguaje cinematográfico. A medida que los estudios semióticos sobre el texto fílmico se distanciaban de aquel patrón epistemológico estructuralista, la Semiótica Narrativa se convirtió en la referencia metodológica que parecía más adecuada al análisis textual del filme y que a su vez derivaría naturalmente hacia los dominios de la Pragmática. La constitución de una subdisciplina autónoma dentro de una Semiótica General de orientación globalmente pragmática, tal como corresponde al pensamiento original de Peirce, y la cada vez más necesaria interdisciplinariedad son los dos fundamentos que están marcando la Semiótica Fílmica del futuro.

La Semiótica Fílmica, en efecto, inició su andadura como una Semiótica Teórica aplicada al estudio de los procesos de significación instaurados por el cine y los textos cinematográficos. En este sentido, la Semiótica del Cine de primera generación consistió esencialmente en adaptar las diferentes Teorías Semióticas en boga en los años sesenta y setenta, de naturaleza fundamentalmente lingüística, a la especulación sobre la semiosis fílmica. En un gesto esencialmente deductivista, la Semiología saussureana o la Semiótica de Hjemslev primero y la teoría greimasiana más tarde sirvieron de plataformas teóricas más o menos adecuadas para tratar de explicar el lenguaje del cine, el término inaugurado por Jakobson en 1933.

En sus primeros balbuceos, la Semiótica del Cine se supedita por completo a la Teoría Lingüística, el modelo central y hegemónico entronizado por la semiología saussureana, y de ahí surgen los debates que en el contexto de aquella incipiente semiótica fílmica sostienen Umberto Eco y Pier Paolo Passolini, Roland Barthes y Christian Metz, Gianfranco Bettetini y Francesco Casetti, sobre la naturaleza sígnica y lingüística del cine, sobre si se trata de un lenguaje o de una lengua y, en este caso, si posee una sola, dos o hasta tres articulaciones. Será el fundador indiscutible de esta nueva 
rama de la Semiótica General, Christian Metz, quien comienza ocupándose de estos problemas puramente linguiísticos al abordar el estudio del significante y el significado en el texto fílmico, de acuerdo con las sugerencias de Barthes, para llegar a la conclusión de que este tipo muy complejo de discurso no puede reducirse a las convenciones de una lengua, puesto que no es descomponible en unidades discretas, sino que su funcionamiento se basaría en una combinatoria de grandes unidades sintagmáticas. El cine es un lenguaje, pero no es de ninguna manera una lengua, en el sentido saussureano del término, puesto que no podemos considerar las imágenes ni como signos ni como unidades semejantes a las palabras, ni organizarlas de acuerdo con una sintaxis gramatical.

Si Passolini contradice explícitamente a Metz, afirmando que sí puede establecerse una lengua del cine aunque ésta no sea articulable en unidades mínimas, pues constituye un sistema de transmisión de significaciones, Bettetini sostiene que existe la doble articulación enunciada por Martinet en el discurso fílmico (iconemas y elementos técnicos), mientras que Eco defenderá la curiosa tesis según la cual el cine es el único código que posee nada menos que tres articulaciones (figuras visuales, semas icónicos y cinemorfemas), triple articulación visual que lo convertiría en uno de los sistemas de comunicación más eficaces y realistas (1968: 243 y ss.).

En la perspectiva metziana de los primeros sesenta, el cine es un lenguaje, un discurso que produce significaciones siempre motivadas, pero en lugar de hacer uso de unidades mínimas semejantes a las del discurso verbal, se basaría en grandes unidades significantes cuya estructuración correspondería no a una sintaxis de tipo gramatical, sino a una retórica que, por otra parte, podría considerarse en cierta forma una gramática. Metz establece, en efecto, una estructuración del filme en unidades sintagmáticas que responderían a una lógica precisa y preexistente, recurriendo para ello a un modelo de origen semiolingüístico, una Sintagmática de naturaleza generativa que lleva su propuesta a un deductivismo insuperable.

El fracaso de este primer modelo metziano estriba en el contraste entre unos fundamentos tan deductivistas y un principio taxonómico de naturaleza inductiva y de carácter semi-empírico, pretendidamente basado en las construcciones empíricas de cineastas, montadores, analistas o teóricos. Fiel al proceder estructuralista, Metz trata de encontrar una lógica (o, mejor, una retórica) preeexistente y subyacente a los textos fílmicos con- 
cretos, pero tal estrategia lingüística se mostrará inadecuada al rigor de los principios de modelización científica, pues, al contrario de las lenguas, los planos y secuencias cinematográficas no se prestan a ninguna sistematización paradigmática ni sintagmática, ni se reducen a una dimensión combinatoria dada, ya que existen tipos combinatorios no repertoriables $o$ inadecuados a esas descripciones estructurales preestablecidas ( $c f$. Chateau, 1990: b3 y b4; Casetti, 1994: 164-165).

No hay que olvidar las bases fenomenológicas de la semiología fílmica de Metz, no en vano sus célebres ensayos sobre la significación en el cine (1968) comienzan reivindicando esa perspectiva y revelan la influencia de la estética cinematográfica de André Bazin. De ahí, su concepción del lenguaje cinematográfico inicialmente antisaussureana y antisemiótica, matizada, eso sí, por una sana cautela ante el modelo científico del que parte cuando advierte que las nociones de la Lingüística deben ser aplicadas a la semiología del cine con la mayor prudencia. Son estas premisas fenomenológicas y bazinianas las que explican la tendencia de Metz a identificar la imagen cinematográfica con la realidad misma y su resistencia a considerarla como signo.

En trabajos posteriores, Metz integrará el estructuralismo hjemsleviano al situar en la forma de los filmes el objeto de la Semiología del Cine, la cual se ocupará no solamente del significante, de la forma de la expresión, sino especialmente de la forma del contenido, de la significación. Si estos primeros trabajos semiológicos de Metz marcarán decisivamente el desarrollo posterior de la Semiótica del Cine, el núcleo de Langage et Cinéma será el que inspirará el análisis textual fílmico de las dos últimas décadas. Abre aquí Metz, en contradicción consigo mismo, otra de las vías fecundas para el estudio semiótico del cine cuando recurre a la teoría de los códigos, poniendo de relieve la heterogeneidad de lenguajes y sistemas, de códigos que configuran el discurso fílmico, dotándolo de su extraordinaria potencialidad comunicativa. La delimitación y descripción de los códigos cinematográficos abre, en efecto, uno de los más fecundos y clarificadores campos de investigación sobre la semiosis cinematográfica, impulsado por un Metz contradictorio, que pese a sus propias propuestas se da cuenta de que la Semiótica del Cine es necesaria. Este nuevo camino será continuado por Eco, Garroni y Bettetini en Italia; Lotman e Ivanov en la entonces Unión Soviética.

Una segunda fase de la evolución de la semiología del cine, lo que Casetti llama la segunda semiótica (1994), vendría impulsada por el 
método científico contrario a las propuestas greimasianas, llevadas a sus últimas consecuencias por Fontanille en su Semiótica del observador: frente a un deductivismo estéril por abstracto y no pocas veces abstruso, el método inductivo fundamenta el conocimiento de la semiosis fílmica en el análisis textual de los filmes concretos. Esta nueva estrategia epistemológica, que encuentra sus fundamentos en la Semiótica Narrativa, gracias al rápido desarrollo de una Narratología Fílmica ya comentado, parece más adecuada para abordar el estudio de la forma y el sentido de filmes concretos, además de permitir, como sugiere Chateau (1990: b5), la confrontación entre las estructuras teóricas tal como los modelos las predicen y las estructuras concretas tal como los filmes las realizan.

La investigación semiótica del cine, basada en la práctica empírica del análisis de secuencias o incluso de planos, de textos fílmicos y de filmografías, de géneros y de escuelas, supone el abandono del estructuralismo formalista y una redefinición de su objeto que libera a la Semiótica Fílmica del lastre metadeductivista. De todos modos, el análisis textual fílmico que llega hasta hoy no deja en ningún momento de contrastar las conclusiones y datos empíricos obtenidos con los modelos teóricos semióticos y pragmáticos utilizados, de forma que no se reduce a la descripción de los filmes, sino que trata de alcanzar nuevos y más profundos conocimientos sobre lo fílmico. Tal como apunta Casetti (1994: 170), los análisis textuales fílmicos, junto al interés descriptivo por su objeto, desarrollan también un interés por discutir las categorías empleadas o incluso de proporcionar otras nuevas, «por eso no se trata únicamente de ejercicios de aplicación, sino también a menudo de auténticas exploraciones teóricas».

Dado que el propio concepto de texto es un concepto pragmático, pues designa la realización concreta de una acción comunicativa, el análisis del texto fílmico derivó naturalmente hacia una Pragmática del Cine o hacia una Semiótica del Cine pragmáticamente orientada, tal y como la ideó originalmente su fundador, Charles Sanders Peirce. El estudio de la comunicación cinematográfica, de su funcionamiento comunicativo específico y de los complejos factores que en ella participan, va a ser el fecundo campo que se inicia a principios de los ochenta y culmina a finales de siglo. A la consideración del filme como proceso textual de práctica significante, de producción de sentido (Bettetini, 1975), propia de la Semiótica de los años setenta, va a suceder su consideración como entidad comunicativa destinada al espectador, categoría activa que a su vez adquiere cada vez mayor importancia (Casetti, 1980, 1986, 1994: 169; 
Browne, 1982). En la línea de trabajos comparatistas abierta por Chatman, en su retórica de la narración fílmica, Browne aborda el análisis del filme desde la perspectiva del intercambio comunicacional entre su enunciador y su receptor, entidades inscritas en el propio texto como narrador/autor y narratario/espectador (1982: 42 y 58).

Esta orientación pragmática de los estudios cinematográficos se plantea esencialmente la cuestión de los mecanismos de enunciación y recepción del cine. Se trata, en primer lugar, de saber si el filme, como el relato escrito, posee alguna instancia fílmico-narrativa que asuma la responsabilidad total del relato, su puesta en imagen. Parece generalmente aceptada la existencia de una fuente ilocutoria, aunque no hay acuerdo en su estatuto y naturaleza: personal o impersonal, mecánica o antropomórfica, textual o real... Si suele hablarse de un narrador cinematográfico lo cierto es que, siendo el narrador el enunciador natural del texto narrativo verbal, de la novela, parece necesario encontrar otra noción que convenga mejor a la naturaleza y funcionamiento comunicativo del texto fílmico, de naturaleza audiovisual. Desde Chatman, Bordwell o Casetti hasta Gaudreault, Jost o Burgoyne, se sostiene la necesidad de un narrador fílmico, entidad paralela al narrador responsable del relato verbal de ficción. Hay que poner de relieve que esta equivalencia conceptual es engañosa, ya que para el fundador de la narratología, Genette, el narrador es ante todo alguien que habla, una voz, mientras que para Jost es alguien que cuenta algo y para Burgoyne, alguien que cuenta... una historia ficcional.

El deslizamiento conceptual es apenas perceptible, pero sus consecuencias son cuando menos contradictorias: si el narrador corresponde en el texto narrativo a la pregunta ¿quién habla? (Genette, 1983: 43), acción esencialmente verbal, Jost cita al autor de Nouveau discours du récit, pero da una definición distinta, «quelqu'un qui raconte»(1983:196), alguien que cuenta algo, por tanto mediante una voz. Cuando Genette pide que se diferencie entre voz y modo, narración y focalización, quién habla y quién ve, su discípulo interpreta: «il faut donc tracer la frontière entre raconter et voir» (1983: 196); es, pues, necesario trazar la frontera entre contar y ver. En adelante, el narrador ya no es el que cuenta por medio de una voz, puesto que puede contar algo por medio de imágenes filmadas, secuenciadas y montadas de determinada forma.

Dado que la Semiótica Fílmica debe alcanzar su autonomía epistemológica e independizarse de la Semiótica Literaria, es necesario que se dote 
de instrumentos conceptuales y metodológicos propios y exclusivos ya que su objeto, el texto fílmico, es propio y exclusivo, razón por la cual parece conveniente proponer una nueva y más rigurosa denominación y definición del enunciador fílmico. La necesidad de dar un tratamiento visual a los problemas de la narración llevó a los semiólogos del cine a recurrir a conceptos tradicionales como perspectiva, punto de vista (Branigan, 1984) o narratológicos como focalización, acertadamente revisado por Jost y sustituído en caso del texto fílmico por ocularización (Jost, 1987). Mientras que Branigan se refiere esencialmente a los planos subjetivos, en los que un personaje se erige en narrador al identificarse su visión con la cámara, Jost explica el fenómeno mediante el concepto más riguroso y exacto de ocularización interna primaria o secundaria.

En el V Congreso de la AISS, en la Universidad de California en Berkeley, presenté una contribución sobre el funcionamiento pragmático del texto fílmico, su enunciación y recepción, proponiendo la noción de cinerrador (cinémateur), como responsable de la enunciación/narración fílmica (Paz Gago, 1998a). Se trata de una entidad textual, ficcional y visual, que debe entenderse en paralelismo con la noción de narrador verbal, pero sin confundirse con ella: el narrador de la novela es una proyección ficcional del autor real, de su voz, integrada en el mundo de la ficción narrativa, mientras que el cinerrador es una proyección ficcional del complejo sistema visual y técnico de realización cinematográfica. Puesto que el narrador se define como una voz que cuenta la historia, el cinerrador será una mirada sobre la historia contada en la película.

Más que en ningún otro fenómeno de semiosis, en el texto fílmico la enunciación/narración y la recepción son procesos simultáneos y convergentes, tal como ya adivinaban las aproximaciones más solventes desarrolladas en la década de los ochenta: la enunciación como mirada al mundo y la recepción como identificación con esa mirada por parte del espectador (Aumont, 1983; Jost, 1983; Bettetini, 1984; Casetti, 1986). Puesto que se trata de un texto visual de ficción, el enunciador o cinerrador es también una entidad ficcional y, en consecuencia, el espectador debe proyectar una personalidad de ficción para introducirse en el universo de la ficción fílmica y percibir el filme con todas sus consecuencias cognitivas, sensoriales y emocionales (Paz Gago, 1998a: 66).

La última década del siglo XX se abría con una serie de mise au point sobre el estado de la cuestión en los estudios de Semiótica Fílmica. 
Burgoyne (1990), Chateau (1990) y Jost (1992) comenzaban preguntándose si las aportaciones conceptuales de la Semiología de los años sesenta, transpuestas al cine sin mayor reflexión, no se habían aplicado irreflexivamente, sin tener en cuenta la naturaleza específica del medio y del soporte del que se trata (Chateau 1990: b1). Las tres perspectivas de conjunto coincidían en poner de relieve que el modelo científico, conceptos y definiciones, deberían ser ajustados convenientemente a su nuevo dominio de aplicación. Ya cuando François Jost proponía una Narratología Comparada, advertía que no se trataba tanto de establecer semejanzas entre sistemas semióticos diferentes sino de aportar a la propia disciplina instrumentos de análisis más precisos (1988: 21) .

El objeto, en efecto, de ambos dominios de la Semiótica Textual es semejante, se trata en ambos casos de un texto narrativo de ficción, lo que cambia es el soporte material, el papel y el celuloide, el libro impreso y la pantalla, así como la naturaleza de los sistemas sígnicos dominantes, icónico-indiciales y simbólicos, imágenes con palabras y palabras con imágenes fijas ocasionales, además de la consecuente complejidad del funcionamiento de los sistemas que los organizan, los códigos. Esas diferencias materiales, formales y semióticas propiamente dichas dan lugar a procesos de enunciación y recepción a la vez semejantes y diferentes, que deben ser estudiados por ramas de la Semiótica bien diferenciadas, la Semiótica Literaria por una parte y la Semiótica Fílmica por otra.

\subsection{Interferencias}

A partir de las convergencias y divergencias, puede abordarse el sistema de interferencias que se dan entre texto literario y texto fílmico: desde las voces narrativas de la novela que son explotadas por el film a través de voces off y over hasta las estrategias visuales que la novela siempre ha utilizado, pues dispone de múltiples recursos para expresar la visualidad.

\footnotetext{
${ }^{4}$ A partir de los códigos de manifestación universal de Metz, códigos presentes en distintos materiales, Jost propone establecer una estrategia móvil para tratar de establecer las diferencias entre sistemas semióticos y facilitar los problemas planteados en un dominio concreto, de forma que, de ese modo, podrían resolverse mejor algunas cuestiones lejos del terreno en el que han surgido (1988: 22).
} 
Una primera interferencia necesaria entre texto verbal y texto visual es precisamente el guión, texto híbrido de naturaleza lingüística en el que se exhiben todos los recursos cinematográficos que serán utilizados en la filmación, el montaje y la postproducción. Hasta el momento se ha descuidado, en los estudios comparados de literatura y cine, la atención a este elemento esencial del proceso transpositivo. Verdadero gozne en el trasvase de un sistema esencialmente verbal a un sistema visual-verbal, el guión literario adaptado conserva la modalidad de la escritura a la vez que debe aportar las soluciones visuales o aplicar las estrategias del montaje. Aunque, efectivamente, desde una perspectiva semiótica interesa esencialmente el texto artístico final que llega al receptor, lo cierto es que en un estudio teórico y comparativo de las relaciones entre literatura y cine es del máximo interés tener en cuenta el guión, máxime cuando hoy en día empieza a ser habitual la publicación de guiones adaptados u originales, que incluso en ocasiones se convierten posteriormente en novelas.

Género híbrido a medio camino entre lo verbal y lo visual, entre lo puramente novelístico y los específicamente cinematográfico, se trata de una pieza literaria que se redacta con la finalidad práctica de realizar la película, «para servir de guía o recordatorio, tanto visual como auditivo, al futuro realizador de la imágenes del filme» (Riambau y Torreiro, 1998: 11). La redacción del llamado guión adaptado es, pues, un paso intermedio para el caso de la transposición fílmica de una novela, el primer paso del proceso transpositivo, pero definitivo ya para la consecución de la película. Ahí se producen las primeras configuraciones cinematográficas de la versión verbal de la historia: su visualidad, la planificación, la selección de acciones y diálogos... Como señala Sellari, el guión «es visual, quien escribe tiene que ponerse en el lugar de quien lee la película» (1998: 33). El guión literario tiene su propia consistencia e incluso puede tener un valor artístico independientemente de su finalidad práctica, a la que hasta ahora se sacrificaba, sin encontrar posteriormente otra posibilidad de salir a la luz pública.

Desde el punto de vista narrativo, el guión es el primer desarrollo textual de la historia que se va a filmar, en donde deben decidirse ya los recursos esenciales de la narrativa fílmica que serán utilizados, también si se trata de una historia que ha encontrado su plasmación en un texto novelístico o dramático anterior, caso en el que habrá que decidir si se explotan los mismos recursos del hipotexto o si se sustituyen por otros. En este sentido, el guión constituye el inicio, la primera forma imperfecta de un 
filme que posiblemente existirá un día, pero que en todo caso tiene oportunidad de existir (Carrière, 1998: 11 y 54). Aproximación máxima de lo literario y lo fílmico, el texto guionístico condensa extraordinariamente la narratividad abstracta y general de la que participan en pie de igualdad cine y novela, convirtiéndose en lugar privilegiado de esta interferencia interartística.

Otro aspecto central de la interferencia entre los dos sistemas de expresión es uno de los componentes esenciales del texto narrativo, la descripción. Tanto la descripción referencial o representativa, propia de la novela realista, como la expresiva y creativa, necesitan de la visualidad. En efecto, la descripción exterior de personajes, objetos, lugares o paisajes es necesariamente visual, pues trata de mostrar al lector el aspecto visible de los seres o espacios descritos. De hecho, la tradición Retórica incluye un amplio espectro de figuras de pensamiento vinculadas a la Descripción o Écfrasis cuya realización textual tiene como finalidad «mostrar o poner ante los ojos» del receptor el objeto descrito, mediante la enumeración de sus propiedades o características más destacadas, reales o fingidas. Mucho antes de que las tecnologías audiovisuales ofreciesen la posibilidad de contar historias ficcionales visualmente, la narración verbal oral o escrita disponía de procedimientos eficacísimos para «al vivo poner las cosas delante de los ojos, y de tal manera expresa alguna cosa, persona, lugar y tiempo, que más parece que se está viendo que oyendo o leyendo...» tal como define Correas en el Arte de la lengua española castellana (1626) la Demostración o Descripción, llamada en estos casos Energía o Evidencia.

No sólo, por tanto, la narrativa verbal dispone de recursos explícitos o retóricos para visualizar personas y lugares de ficción, sino que esta percepción visual sugerida verbalmente puede ser actualizada sin mayor problema por el receptor en su imaginación. Esta visualidad literaria, por otra parte, responde perfectamente en la novela al código cinematográfico de la planificación, no por inspirarse directamente en él, sino porque tal código responde a las posibilidades físicas de la percepción visual. Si la escala de planos que ofrece la fotografía o el cine responde al modo de mirar el objeto filmado, desde más cerca en Primerísimo Primer Plano o Plano de detalle hasta lo más lejos posible, en Gran Plano General, exactamente lo mismo ocurre en la visualización verbalizada, que dispone de las mismas posibilidades para expresar ese acercamiento o alejamiento. Las descripciones pueden mostrar la realidad (ficcional) descrita desde más 
cerca o desde más lejos, desde arriba o desde abajo, estáticamente o en movimiento, horizontal o vertical, tal como lo hace el texto fílmico mediante el uso de la escala de planos, sus ángulos y sus movimientos de cámara. Es por esta razón por la que cualquier descripción de una novela, aunque no haya recibido el impacto de la tecnología audiovisual, puede responder perfectamente al código de la planificación, tal como han puesto de manifiesto numerosos investigadores, desde Eisenstein a Umberto Eco o Darío Villanueva.

Si la descripción de Rouen en Madame Bovary plasma un Gran Plano General de lozalización, la apertura de I promessi spossi de Manzoni es comparable a un completo y perfecto zoom cinematográfico para Eco (1985), como la descripción de Vetusta en el primer capítulo de La Regenta constituye, para Villanueva (1999a: 191), una hábil panorámica aérea de la ciudad desde el objetivo del famoso catalejo. Pierre Danger (1973: 213), por su parte, vislumbra el lenguaje cinematográfico en La educación sentimental de Flaubert haciendo un completo découpage en planos y secuencias 5 .

La narración basada en el código del montaje o la descripción de acuerdo con el código de la planificación son, por supuesto, mucho más evidentes en la novela del siglo XX, el siglo del cinematógrafo, influida ya directamente por el modo de ver la realidad propia del relato fílmico. La tantas veces citada obra de Magny sobre la novela norteamericana de los años veinte incide en esa idea de la forma característica de mirar el mundo que el cine transmite y que determina necesariamente la técnica narrativodescriptiva de los novelistas cinéfilos. El fenómeno de los cortes elípticos bruscos o de los pasajes que describen personajes o lugares, objetos y espacios, en la clave planificada y fragmentaria de la mirada cinematográfica se radicalizan a partir de la difusión masiva del cinematógrafo.

Es conocido el impacto del texto fílmico en el Realismo objetivista, caracterizado por la presencia de imágenes visuales y por marcar continuamente las focalizaciones o perspectivas cognitivas y narrativas de la acción narrada, fenómeno que, en la interpretación de Buckley (1973: 38-

5 La crítica despiadada de Company (1987: 27-28) a estas páginas de Danger tiene poco fundamento y cae en lo que critica, pues toma las justas apreciaciones del crítico en sentido ingenuamente literal, sin tener en cuenta que se trata de una analogía. 
39 y 40-44), habría hecho patente una lógica del enfoque visual de las cosas y de las situaciones que los novelistas aprovechan en sus narraciones. Este nuevo realismo objetalista, definido primero como Escuela de la mirada, se convertirá en el Nouveau Roman, movimiento paralelo al cinematográfico de la Nouvelle Vague que basa precisamente la estructura narrativa en la descripción visual focalizada. Novelistas como RobbeGrillet construyen un punto de vista del narrador, quien enfoca la realidad y selecciona lo que nos muestra de ella, para describirla con toda objetividad, como si de una cámara de cine se tratase.

Si el realismo decimonónico disponía de estas estrategias presentativas y referenciales, es claro que el procedimiento está ahora filtrado y perfeccionado por la experiencia visualizante cinematográfica, cuyo hipoiconismo intensifica el efecto de realidad. La novela objetalista española, desde El Jarama de Sánchez Ferlosio a Tormenta de Verano de García Hortelano, explota las técnicas neorrealistas de raigambre fílmica como la traslación directa de los diálogos, el observador exterior que focaliza los pasajes descriptivos, los ángulos y encuadres que formalizan la presentación de la realidad descrita... En este sentido, el llamado perspectivismo cinematográfico, en paralelo con la descripción subjetiva, es otro rasgo presente en la narrativa verbal del pasado que se impone definitivamente gracias a los procesos de ocularización externa e interna con los que nos familiarizó definitivamente el cine.

También los movimientos de cámara están presentes en la narrativa verbal de antes y de después del invento de los hermanos Lumière, que puede hacer uso de continuos desplazamientos visuales para acompañar a un personaje, moviéndose de grupo en grupo, para recoger frases e imágenes fragmentarias de lugares diferentes. En la obra citada de Pierre Danger, por ejemplo, se analiza un complejo movimiento horizontal y vertical de cámara en el puerto: un lento travelling entre la agitación de los marineros, de los fardos y los pasajeros... a continuación, la cámara se eleva mediante un efecto grúa para seguir la subida de un fardo... (1973: 213).

Entre novela y cine todas estas interferencias son incuestionables y deben jugar un papel fundamental en el estudio comparativo de ambos sistemas narrativos ficcionales, que son a la vez análogos y diversos. Lo expresaba, desde el campo estrictamente fílmico, Fernando Trueba, un director de cine poco dado a la práctica de la transposición de textos literarios: 
Junto a ellos y otros -Renoir, Keaton, Sturges, Ford, Hitchcock, Buñuel...-Wilder forma parte de ese Olimpo cinematográfico que agrupa a aquellos que han hecho del cine un género literario tan noble como el que más y que lo han situado en el lugar que merece en la historia del Arte. Porque el cine es Literatura, es un texto que se escribe con imágenes y sonido, rostros y palabras, cuerpos y gestos, emoción y movimiento, luz y silencio sobre un papel hecho de tiempo 6 .

\section{REFERENCIAS BIBLIOGRÁFICAS}

Aumont, J. (1983). «Points de vue: l'oeil, le film, l'image». Iris 1/2.

— (1984). «L'image filmique du film», Revue d'esthétique, 7.

- (1990). L'image. Paris: Nathan, $2^{\text {a }}$ ed. 1994.

Aumont, J. y Marie, M. (1988). L'analyse des films. París: Nathan. Ed. esp.: Análisis del film, Barcelona: Paidós, 1990.

Browne, N. (1982). The Rhetoric of Filmic Narration. Ann Arbor: UMI Research Press.

Buckley, R. (1973). Problemas formales de la novela española contemporánea. Barcelona: Península.

Burgoyne, R. (1990). «The Cinematic Narrator. The Logic and Pragmatics of Impersonnal Narration». Journal of Film and Video 42/1. Trad. fr.: «Le narrateur au cinéma. Logique et pragmatique de la narration impersonnelle», Poétique 87, 1991, 271-288.

Carmona, R. (1991). Cómo se comenta un texto fílmico. Madrid: Cátedra.

CARRìtre J. Cl. (1998). «Prólogo y El contador de historias». En Taller de escritura para cine, Vilches, L. ed., 9-11 y 47-72. Barcelona: Gedisa.

Casetti, F. y de Chio, F. (1990). L'analisi del film. Milano: Bompiani. Ed. esp.: Cómo analizar un film, Barcelona: Paidós, 1991.

6 Catálogo de la Exposición dedicada a Billy Wilder. En Babelia, El País, 23 de noviembre de 1996. 
Cattryse, P. (1992a). Pour une théorie de l'adaptation filmique. Le film noir américain. Bern: Peter Lang.

- (1992b). «Film (Adaptation) as Translation: Some Methodological Proposals». Target. International Journal of Translation Studies 4/1, 53-70.

- (1994a). «The Study of Film Adaptation: A State of the Art and some New Functional Proposals». En Trasvases culturales: literatura, cine, traducción, Eguiluz, F., ed., 37-55. Vitoria: Universidad del País Vasco.

- (1994b). «Pour une approche intersystématique du cinéma». En Towards a Pragmatics of the Audiovisuel. Theory and History, Müller, J. ed., vol. 1, 61-76 Münster: Nodus Publikationen.

Clerd, J. M. (1983). «Littérature et cinéma». En La recherche en Littérature Générale et Comparée en France 157-171. Paris: SFLGC.

- (1985). Écrivains et cinéma: Des mots aux images, des images aux mots. Adaptations et ciné-romans. Paris: Presses Universitaires de Metz.

- (1989). «La literatura comparada ante las imágenes modernas: cine, fotografía, televisión». En Précis de littérature comparée, Brunel, P. y Chevrel, Y. eds., Paris: PUF. Ed. esp.: Compendio de Literatura Comparada, México: Siglo XXI, 1994, 236-273.

— (1993). Littérature et cinéma. Paris: Nathan.

Company, J. M. (1987). El trazo de la letra en la imagen, Texto literario y texto fílmico. Madrid: Cátedra.

- (1989). «La conquista del tiempo. Las adaptaciones literarias en el cine español». En Escritos sobre el cine español 1973-1987, 79-88 Valencia: Filmoteca de la Generalitat Valenciana.

- (1996). «Las voces de la novela y las huellas de la imagen». Moenia, 2, 259-265.

Chateau, D. (1986). Le cinéma comme langage. Paris: Publications de la Sorbonne.

- (1990). «La sémiologie du cinéma: un bilan». Degrés, 64, b1-b9.

(1993). «Sémiologie et philosophie ou comment poser la question: «Le cinéma est-il un art?». Recherches Sémiotiques/Sémiotic Inquiry, 13/12, 149-160. 
DANGER, P. (1973). Sensations et objets dans le roman de Flaubert. Paris: Armand Colin.

ECO, U. (1962). «Cinema e letteratura: la struttura dell'intreccio». Film Selezione, pp. 13-14. En La definizione dell'arte, Milano: Mursia, 1968, 201-08. Ed. esp.: Barcelona: Martínez Roca, 1970: 194-200.

- (1963). «Un balance metodológico». Times Literary Supplement, 27.IX. En La definizione dell'arte, Milano: Mursia, 1968, 201-08. Ed. esp.: Barcelona: Martínez Roca, 1970, 278-285.

- (1968). La estructura ausente. Milán: Bompiani. Ed. esp.: Barcelona: Lumen, 1989.

- (1977). «On the Contribution of Film to Semiotics». Quarterly Review of Film Studies 2/1: 1-14.

- (1980). «Towards a Semiotic Inquiry into the Television Message». Communication Studies, Corner, J. \& Hawtorn, J. eds., 131-149 London: Arnold.

— (1985). «Panorámica con travelling». El País, 7.III.

Eisenstein, S. M. (1933). «Cine y literatura (Sobre lo metafórico)». Ed. esp.: Cinematismo, Buenos Aires: Domingo Cortizo Editor, 1972.

- (1934) . «Del teatro al cine». Sovetskoe Kine, 11/12, 54-83. Ed. esp.: Madrid: Rialp, 1959.

- (1942-1948). Film Form and Film Sense. Cleveland: Meridian, 1957. Ed. esp.: La forma del cine, Buenos Aires: Siglo XXI Argentina, 1974 y 1986.

- (1944). «Dickens, Griffith y nosotros». En Reflexiones de un cineasta, Madrid: Artiach, 1970: 180-236. $2^{\mathrm{a}}$ ed.: Barcelona: Lumen.

FELL, J. (1977). El filme y la tradición narrativa, Buenos Aires: Tres Tiempos.

FERnÁndEZ, L. M. (1994). «Metanarración, intertextualidad y paradoja. Del cine de Bardén, a la novela de Marsé». Letras Peninsulares 7/1: 251-275.

- (1996). «La transgresión del canon en la narrativa española contemporánea. El simulacro fílmico en Marsé y Llamazares». Moenia 2, 293307. 
- (2000). Don Juan en el cine español. Hacia una teoría de la recreación fílmica. Santiago: Universidade de Santiago de Compostela.

- (2002). «A recreación fílmica: problemas e métodos». Boletín Galego de Literatura 27, 165-181.

Genette, G. (1969). Figures III. Paris: Seuil.

- (1983). Nouveau discours du recit. Paris: Seuil.

— (1991). Fiction et diction. Paris: Seuil.

— (1999). Figures IV. Paris: Seuil.

GonZÁlez ReQuena, J., ed. (1995). El análisis cinematográfico. Modelos teóricos. Metodología. Ejercicios de análisis. Madrid: Universidad Complutense.

Hamburger, K. (1957). Die Logik der Dichtung, Stuttgart: E. Klett, $2^{\mathrm{a}}$ ed. 1968. Ed. esp.: Madrid: Visor, 1995.

JAKOBSON, R. (1933). «Úpadek filmu?». En Listy pro umeni a Kritiku, I, Praga, 45-49. Ed. ingl. Cinema \& Film, I/2, 1967, 163-168. Ed. port.: R. Jakobson. Lingüística. Poética. Cinema, Sâo Paulo: Perspectiva, 1970: 153-161.

- (1967). «Entretien sur le cinéma avec Adriana Aprá et Luigi Faccini». En Cinéma: Théorie, lectures, Noguez, D., ed., Revue d'Esthétique 26/2-4, 61-68.

Jost, F. (1987). L'Oeil-caméra. Entre film et roman. Lyon: Presses Universitaires de Lyon. $2^{\text {a }}$. ed. aum. 1989. Ed. esp.: Buenos Aires, 2001.

- (1988). «Propuestas para una Narratología Comparada», Discurso, 2: 21-32.

- (1992). Un monde à notre image: énonciation, cinéma, télévision. Paris: Klincksieck.

- (1994). «Direct, narration simultanée: frontières de la temporalité». Cinémas 5-1/2, 81-90.

- (1996). «Propositions pour une typologie des documents audiovisuels». Semiotica 112.1/2, 123-140. 
- (1998). Le temps d'un regard. Du spectatteur aux images. Québec et Paris: Nuit Blanche et Klicksieck.

- (1999). «L'épiphanie filmique». En Cien años de cine. Historia, Teoría y Análisis del texto fílmico, Castro de Paz, J. L., Couto Cantero, P. y Paz Gago, J. M., eds., 43-59. Madrid: Visor.

KLARER, M. (1999). An Introduction of Literary Studies. London: Routledge.

Metz, Ch. (1968). Essais sur la signification au cinéma, I, Paris: Klincksieck, $2^{\text {a }}$ ed. 1983. Ed. esp.: Buenos Aires: Tiempo Contemporáneo, 1972.

- (1971). Langage et Cinéma, Paris: Larousse. Ed. esp.: Barcelona: Planeta, 1973.

- (1968). Essais sur la signification au cinéma, II. Paris: Klincksieck, 2a ed. 1981.

—(1977a). Le signifiant imaginaire. Paris: U.G.E., $2^{\text {a }}$ de. 1993. Ed. esp.: Psicoanálisis y cine, Barcelona: Gustavo Gili, 1979.

- (1977b). Essais Sémiotiques. Paris: Klincksieck.

- (1987). «L'énonciation impersonnelle, ou la site du film». Vertigo 1, 13-34.

-(1991). L'Enonciation impersonnelle, ou la site du film. Paris: Klincksieck.

Mínguez, N. (1998). La novela y el cine. Análisis comparado de dos discursos narrativos. Valencia: Ediciones de la Mirada.

Mortier, R. (1981). «Cent ans de Littérature Comparée: L'acquis, les perspectives». En Actes du IX $X^{e}$. Congrès de l'Association Internationale de Littérature Comparée, Konstantinovic, Z. et al. eds., vol. 1, 429-437. Innsbruk: ISUI.

Paz Gago, J. M. (1995). Semiótica del Quijote. Teoría y práctica de la ficción narrativa. Ámsterdam y Atlanta: Rodopi.

- (1998a). «Énonciation et reception au cinéma: Le cinémateur». Caiet de Semiotica (Timisoara) 12, 61-69. 
- (1998b). «Les aventures de Don Quichotte de la Manche (1902/03), primer filme de la historia». En Cervantes en imágenes, RosA, E. de la, GonZÁLeZ, L. M. y Medina, P. eds., 159-166. Alcalá: Festival de Cine de Alcalá de Henares.

- (1999). «Teoría e Historia de la Literatura y Teoría e Historia del Cine». En Cien años de cine. Historia, Teoría y Análisis del texto fílmico, Castro de Paz, J. L., Couto Cantero, P. y Paz Gago, J. M. eds., 197-212 Madrid: Visor.

- (2000a). «La escritura cinematográfica de Gonzalo Torrente Ballester». En Gonzalo Torrente Ballester y el cine español, Castro de Paz, J. L. y Pérez Perucha, J. eds., 117-130 Ourense: Festival Independiente de Cine de Ourense.

- (2000b). «Escritores de cine. nuevo cine y nueva narrativa latinoamericana». Anales de Literatura latinoamericana 21, 43-74.

- (2002). «Teorías semióticas y semiótica fílmica». Cuadernos de Semiótica $17,125-140$.

PEÑA-ARDID, C. (1992). Literatura y cine. Una aproximación comparativa. Madrid: Cátedra.

- (1996). «Rupturas de la mímesis (nuevas reflexiones sobre las influencias del cine en la novela)». Moenia 2, 225-242.

- (1999). «La imagen y el imaginario fílmico en la novela española contemporánea». En Encuentros sobre Literatura y Cine, 37-64. Zaragoza: Instituto de Estudios Turolenses.

PÉREZ BowIE, J. A. (2003). «La teoría sobre la adaptación cinematográfica de textos literarios. Estado de la cuestión». En La adaptación cinematográfica de textos literarios. Teoría y práctica, Pérez Bowie, J. A. ed., 11-30. Salamanca: Plaza Universitaria Ediciones.

Pichois, C. y Rousseau, A. M. (1967). La Littérature Comparée. Paris: A. Colin. Ed. esp.: La literatura comparada, Madrid: Gredos, 1969, $2^{\mathrm{a}}$ ed., 1985.

Remak, H. H. (1961). «Comparatice Literature. Its Definition and Function». En Comparative Literature: Method and Perspective, 3-7. Carbondale: Southern Illinois University. 
- (1980). «The Future of Comparative Literature». En Actes du VIII . Congrès de l'Association Internatiuonale de Littérature Comparée, Köpeczi, B. y Vajda, G. M. eds., vol. 2: 429-437. Stuttgart: E. Bieber, vol. 2, 429-437.

Riambau, E. y Torreiro, C. (1998). Guionistas en el cine español. Quimeras, picarescas y pluriempleo. Madrid: Cátedra y Filmoteca Española.

Romaguera, J. y Alsina, H., eds. (1993). Textos y manifiestos del cine. Madrid: Cátedra.

SEllari, M. (1998). «Las voces interiores». En Taller de escritura para cine, Vilches, L., ed., 21-46. Barcelona: Gedisa.

TôTÔSY DE ZEPETNEK, St. (1998). Comparative Literature: Theory, Method, Application. Amsterdam y Atlanta: Rodopi.

UrRutia, J. (1984). Imago litterae. Cine. Literatura. Sevilla: Alfar.

VillanueVa, D. (1991). «Posibilidades y límites de los estudios literarios». En El polen de ideas. Teoría, Crítica, Historia y Literatura Comparada. Barcelona: PPU.

- (1994). «Literatura Comparada y Teoría de la Literatura». En Curso de Teoría de la Literatura, Villanueva, D., coord., 99-127. Madrid: Taurus.

- (1999a). «Novela y cine, signos de narración». En Encuentros sobre Literatura y Cine, 185-210. Zaragoza: Instituto de Estudios Turolenses, pp.

- (1999b). «Los inicios del relato en la literatura y el cine». En Cien años de cine. Historia, Teoría y Análisis del texto fílmico, Castro de Paz, J. L., Couto Cantero, P. y Paz Gago, J. M., eds., 213-236. Madrid: Visor.

Weisstein, A. (1968). Einführung in die Vergleichende Literaturwissenschaft. Stuttgart: W. Kohlhammer GmbH. Ed. esp.: Introducción a la literatura comparada, Barcelona: Planeta, 1975.

Zunzunegui, S. (1989). Pensar la imagen. Madrid: Cátedra/Universidad del País Vasco, $4^{\text {a }}$ ed. 1998.

- (1994a). Paisajes de la forma. Ejercicios de análisis de la imagen. Barcelona: Paidós. 
- (1996). La mirada cercana. Microanálissi fílmico. Barcelona: Paidós.

- (1999). «El objeto indescriptible». En Cien años de cine. Historia, Teoría y Análisis del texto fílmico, Castro de Paz, J. L., Couto Cantero, P. y Paz Gago, J. M., eds., 35-42. Madrid: Visor. 